\title{
Maternidade e amamentação: identidade, corpo e gênero
}

\author{
Maternity and breastfeeding: identity, body and gender
}

Rubia Carla Formighieri Giordani ${ }^{1}$

Daniele Piccoli ${ }^{1}$

Islândia Bezerra ${ }^{1}$

Claudia Choma Bettega Almeida ${ }^{1}$

\begin{abstract}
Breastfeeding is a multifaceted phenomenon involving the complexity of the social world, the roles assumed by women, their attributes and social expectations. This theoretical essay proposes a reflection on motherhood, problematizing the experience of breastfeeding and the construction of social identity in line with Anselm Levi Strauss's sociological concepts of interactionism. This article sought to make associations between body, identity, and socialization processes in adulthood, generated by new social demands in fulfilling the roles of woman and mother, focusing on the breastfeeding experience. The way motherhood is conceived in contemporary society and the register of breastfeeding as a phenomenon of nature are problematized to give the woman a vocation to motherhood and breastfeeding, producing a social expectation of the innate ability to perform them.
\end{abstract}

Key words Maternity, Breastfeeding, Social identity, Body, Interactionism
Resumo A amamentação é um fenômeno multifacetado que envolve a complexidade do mundo social, os papéis assumidos pela mulher, seus atributos e expectativas sociais. Este ensaio teórico propõe uma reflexão em torno da maternidade, problematizando a experiência da amamentação e a construção de identidade se aproximando de conceitos sociológicos do interacionismo de Anselm Levi Strauss. Procurou-se fazer associações entre o corpo, a identidade e os processos de socialização na vida adulta gerados pelas novas demandas sociais na realização de papéis de mulher e mãe, concentrando-se na experiência da amamentação. Problematiza-se a forma como a maternidade é concebida na sociedade contemporânea e a inscrição da amamentação como fenômeno da natureza, de tal forma que se confere à mulher uma vocação à maternidade e ao aleitamento, produzindo-se uma expectativa social de habilidade nata para o desempenho dos mesmos. Palavras-chave Maternidade, Amamentação, Identidade social, Corpo, Interacionismo
${ }^{1}$ Departamento de Nutrição, Setor de Ciências da Saúde, Universidade Federal do Paraná. R. Lothário Meissner 632, Jardim Botânico. 80210-170 Curitiba PR Brasil. rubia@ufpr.br 


\section{Maternidade e Gênero}

O nascimento de um filho e a responsabilidade pela sua vida provocam mudanças na identidade feminina e implicam em transformações em seus relacionamentos pessoais e no conjunto das relações sociais'. Por um lado, na mudança de sua identidade, a mulher passa a assumir uma nova condição de si, da vida, das relações, dos outros, provocando uma transformação de comportamento, posturas e, finalmente, uma mudança completa na sua autoimagem. E, por outro, a sociedade ao lhe impor papéis, fundamentalmente, exige certos posicionamentos e atitudes que a relegam a uma condição de cumpridora do seu "dever".

Strauss ${ }^{1}$, afirma que a nomeação de um objeto fornece uma diretriz para a ação, e na amamentação se nota o feminino rotulado como sujeito que alimenta, condicionado biologicamente com sua anatomia e fisiologia para a amamentação. A maternidade e a amamentação como papéis sociais atrelam-se, portanto, às questões de gênero e ao debate sobre a condição feminina, questões ligadas fortemente ao que Rodrigues ${ }^{2}$ ponderou sobre a apropriação do corpo pelo discurso ideológico.

Joan $\operatorname{Scott}^{3}$ define que "o gênero é um elemento constitutivo de relações sociais fundadas sobre diferenças percebidas entre os sexos, e o gênero é um primeiro modo de dar significado às relações de poder". O termo gênero se refere à dicotomia da identidade sexual, mas, sobretudo, evidencia as relações de poder e os processos de dominação ligados à distinção sexual ${ }^{4}$. Para os propósitos deste artigo, auxilia na compreensão da naturalização de certas relações de poder que moldam eventos do ciclo de vida feminino na sociedade patriarcal.

O poder permeia as relações entre os sexos, atua nas relações sociais de modo mais amplo representando um poder que disciplina o corpo, controla seus movimentos, usos e finalidade. Estabelece normas que o circunscreve e interpreta o desvio, o imoral e subversivo e o inapropriado. Tais ordens disciplinares, regidas por instituições sociais (escolas, hospitais, ciências, igrejas, prisões, governos) engendram em nossa sociedade a padronização da vida humana e sua otimização para reprodução do capital e a centralização do poder político ${ }^{5-7}$ perpetuando assim o modelo patriarcal de dominação (grifo nosso). O corpo feminino torna-se, assim, patrimônio da ordem social, objeto de uma biopolítica específica para a sua contenção e regulação por normas e valores.
A contenção do corpo feminino à intimidade está ligada à delimitação e definição de uma identidade social para a mulher como mãe e, na opinião de Badinter ${ }^{8}$, envolve conjuntos de instruções sociais sobre como se tornar boa mãe em nome de um dever social e político. Como exemplo, está o próprio desenvolvimento na moderna pediatria dos compêndios de puericultura que vieram a servir na orientação da população feminina sobre como obter um status de boa mãe. Segundo Lima', ilustram a maneira orgânica pela qual o discurso biomédico se articula com a ordem social e a normalização de comportamentos, impondo às mulheres o acesso a determinadas informações que as definem e as localizam em certos lugares de "privilégios" exclusivos da maternidade.

O corpo feminino transpassa os processos biológicos como a fecundação, o nascimento, a natalidade, a mortalidade, tornando-se alvo privilegiado do biopoder ${ }^{7,10}$. O controle e a intervenção social sobre o corpo feminino materno se legitima como um controle sobre a vida, pois a intervenção sobre o corpo afeta de alguma forma o curso natural da vida humana.

Na obra "O segundo sexo", que Simone de Beauvoir ${ }^{11}$ publicou originalmente em 1949, a filósofa afirmava que as relações de maternidade são uma espécie de transição unilateral de mãe para filho ${ }^{11}$. Hird ${ }^{12}$ complementa esta perspectiva analisando que a maternidade está caracterizada por um sistema de doação que consiste na generosidade do corpo materno, o qual se rende ao desejo e dependência do outro, em nome do amor e da felicidade do e para o outro. De fato, o corpo não é apenas carne e matéria, é atravessado pela subjetividade, é o objeto do sujeito, o órgão extensivo que se comunica com o mundo, consciente e inconscientemente, através dos sentidos, sentimentos e expressões ${ }^{13}$. Não é somente biológico, mas é sentimento, dramatização, espetacularização, intuição e problematização ${ }^{13}$. A experiência de amamentar é sobretudo vivenciada pelo corpo feminino: um corpo que é matéria atravessada pela subjetividade provocando $e$ sendo provocada por sentidos produzidos socialmente e, por conseguinte culturalmente ${ }^{14}$.

\section{Proposta teórica e metodológica: um ensaio sobre identidade social e o processo do aleitamento}

Tendo como tema central a maternidade, pretende-se neste ensaio teórico trazer elementos para discutir a identidade materna e a amamentação, como um processo social de (re) constru- 
ção constante da individualidade frente aos novos processos relacionais e demandas sociais envolvidas no papel de mãe. Desse modo, espera-se trazer para a reflexão aspectos sobre a construção social da identidade materna e a problematização do valor da amamentação como desempenho natural esperado da mulher. Segundo o sociólogo Strauss ${ }^{1}$, as identidades não são fixas, mas continuamente redefinidas em processos de socialização presentes na vida adulta. As transformações de identidade envolvem processos de classificação, nomeação de si e de outros, e autorreflexão ${ }^{1}$.

A construção da identidade se dá por meio da descoberta de si: de quem é; qual posição social pertence; e, de que modo pertence. A identidade é renovada à medida que um ciclo da vida encerra e outro inicia, dessa forma, ela é mutável e é passível de constantes autoavaliações e julgamentos $^{1,15}$.

A partir destas considerações iniciais, tomarse-á como linha central de análise a compreensão dos microprocessos sociais e os afazeres cotidianos que estão em jogo na (re) definição da identidade feminina, sobretudo, considerando a vivência da amamentação. Para tanto, serão abordadas as categorias de identidade, me, self, desapossamento, colocação de status e interações sociais, desenvolvidas pelo sociólogo Anselm Lévi-Strauss ${ }^{1}$ em sua obra Espelhos e Máscaras.

Strauss ${ }^{1}$, um expoente da corrente interacionista da sociologia norteamericana conhecida como Escola de Chicago, publicou originalmente sua obra Espelhos e Máscaras em 1959, propondo uma reflexão sobre a socialização na vida adulta. No cenário da vida cotidiana, pela incorporação de papéis sociais regulados e estruturados por uma ordem social específica, Strauss sugere que a realidade social afeta a realidade cognitiva. Estes conceitos serão aplicados neste ensaio com o objetivo de problematizar as rupturas subjetivas e as novas demandas sociais que se impõem à mulher diante da maternidade e do aleitamento materno.

\section{Mulher e mãe: algumas conexões entre identidade social, corpo e gênero}

A identidade social feminina envolve o desempenho de diferentes papéis relacionados às experiências específicas nas quais a mulher se engaja cotidianamente ${ }^{1}$. Essa identificação com papéis é dinâmica e pressupõe uma classificação, a qual permitirá diferenciar, marcar fronteiras e relacionar. Para Strauss ${ }^{1}$, toda classificação gera expectativas, remete ao sujeito a antecipação de valores, condutas, comportamentos previamente experimentados por si ou por outros. Leva a uma série de julgamentos e permite, por exemplo, à mulher a identificação de valores, posturas, práticas corporais socialmente femininas e relações com o papel social que desempenhará ao amamentar. O modelo de sociedade atual com suas instituições (família, escola, igreja) partilha situações forjadas para perpetuar as relações de poder nas práticas cotidianas subordinando a mulher e naturalizando a exclusividade do ato alimentar, o que difere do ato de amamentar.

Desse modo, convém ressaltar que a identidade não é fixa e, ao se transformar, atende as demandas de papéis simultâneos gerando experiências subjetivas diversas. O desempenho destes papéis pelo indivíduo articula processos sociais e culturais às trajetórias biográficas particulares. No caso da identidade feminina, com suas representações sobre o que é ser mãe ou ser mãe que amamenta, não compreende experiências homogêneas e uniformes, pois depende de mundos sociais e subjetividades específicas.

À medida que o indivíduo se depara com novas situações pouco familiares, é necessária a sua apropriação e ampliação de conhecimento sobre o que está vivendo. Toda classificação ou nomeação está sujeita a alguma contestação e a uma reavaliação por si ou por outros, então a ação humana deve ser encarada como algo experimental e exploratório. Enquanto perdurar o aprendizado haverá revisão de opiniões e, consequentemente, a reorganização de comportamentos e reconstrução da identidade. Nesse sentido, uma mulher que passou por uma experiência negativa ou positiva durante a amamentação de seu primeiro filho, necessariamente, não repetirá a mesma experiência, vez que as circunstancias vividas, sentidas e apreendidas serão outras.

A decisão perpassa pelo nível individual, muito embora esteja sob forte influência externa ${ }^{1}$. Mesmo havendo imperativos de ordem social e cultural frente à tomada de decisão pela mulher em cessar ou continuar a amamentação e estes pesarem como motivadores para a ação, independente de sua condição biológica naturalmente favorável para tal ação, a decisão passa pela tarefa da mulher de julgar e autoavaliar sua capacidade e desejo em amamentar. Os anseios e os medos que emergem sobre a amamentação e que são compartilhados pela mulher no ambiente doméstico ou nos espaços de saúde fazem parte deste processo. Deste modo, repensar práticas que impelem as mulheres à culpabilização sobre as consequências desse ato (de não amamentar) é primordial nos diferentes espaços. 
A decisão de amamentar e a manutenção cotidiana do processo pressupõem uma reflexão sobre aquilo que Strauss ${ }^{1}$ denominou de retórica. Um diálogo interior (consciente e inconsciente) que diz respeito a questões que a mulher percebe serem importantes, que podem ser sentidas como uma espécie de perturbação - seja baseada na escolha da amamentação, ou a definição de outras formas de alimentar seu bebê.

A amamentação, em si, é representada como um comportamento natural e instintivo da mulher e socialmente vemos todo o processo do aleitamento muito ligado à esfera feminina. $\mathrm{O}$ ato de amamentar é um valor de status atribuído pela sociedade à maternidade e ao cuidado da criança ${ }^{16}$, sendo o engajamento feminino construído e preparado pela socialização da mulher ao longo de sua vida. Sua subjetividade é integrada às dinâmicas sociais pelos papéis e espaços que ocupa, produzindo-se aí situações de aprendizado e experiências compartilhadas sobre o ser mulher, o ser mãe e a vivência da amamentação.

Strauss ${ }^{1}$ menciona que, à medida que o ser humano julga seus próprios atos, este se torna seu próprio objeto classificado pela autoavaliação: o self (olhar para si). A posição ou papel ao qual o indivíduo pertence ou se deixa pertencer, está ligado à forma como este se percebe em relação aos outros: quando assume o papel de sujeito está em estado de empoderamento de si e das suas relações interpessoais, ao passo que, ao assumir ou aceitar o papel de objeto, está condicionado e tacitamente comprometido com certa imposição externa.

A expressão do self relaciona-se a um autorretrato e Strauss ${ }^{1}$ faz referência ao me para explicar o self. O me é o objeto julgado pelo eu sujeito, é o ato avaliado. No dicionário, o me é designado como pronome pessoal oblíquo de primeira pessoa, no singular, cuja funcionalidade se caracteriza como objeto direto ou indireto ou como uma partícula de interesse, como parte integrante a uma ação verbal, como sujeito infinitivo para uma ação ${ }^{17}$. O self representa o sujeito tal qual como se revela e se conhece, representado pela sua própria consciência.

O self surge de uma autoavaliação ao fazer questionamentos relativos às experiências passadas, dos aspectos motivacionais, atitudinais e relacionais de tudo que possa estar supostamente por trás dos atos (um self essencial). A autoavaliação conduz o indivíduo a uma tomada de decisão, seja para evitar repetir atos, fazer correções, (re) criar caminhos para a ação ${ }^{1}$. Interpretando estes conceitos e aplicando-os em uma reflexão sobre a amamentação, o self é o exercício que a mulher faz ao se autoavaliar, olhar para si, para os mes (por exemplo, aquele decorrente de uma experiência pregressa sobre amamentar) para então refletir e decidir pelo aleitamento materno e/ou sua continuidade, ponderar sobre sua motivação, desejo e capacidade em mantê-lo, avaliar os desafios que poderá enfrentar durante o processo da amamentação, e em que medida esta pode afetar seu bem-estar e suas relações com os outros.

Segundo Strauss ${ }^{1}$, o eu como sujeito e protagonista da ação ao rever seu me como objeto se move continuamente para um futuro, que parcialmente ainda não foi programado fazendo emergir os novos eus e mes, de atos avaliadores e avaliados. Esse movimento entre o eu e o me, compara-se a imagem no espelho, quando o eu é capaz de olhar para si (ou uma parte de si). Assim, destas autoavaliações e do fato que o futuro ao ser incerto e as ações humanas um tanto exploratórias, os erros e as perdas fazem parte da experiência social.

Nesta essência problemática do mundo social para o indivíduo, Strauss" "coloca a possibilidade de perigo e desapossamento de algo valioso, caro ao indivíduo e para o qual tenha havido grande investimento social e subjetivo"; uma perda ou desapossamento de objetos (como o me) que marcam as definições de identidade do indivíduo. No caso, a mulher a partir de seu papel de mãe, ou do nascimento de um(a) novo(a) filho(a) ao iniciar o processo da amamentação se depara com novas performances corporais, novas emoções que emergem do contato corporal com seu bebê, outros significados e valorações de seu corpo e seios. Um dos espectros produzidos pela problematização destas experiências pode se expressar na sensação de perda de autonomia de seu corpo. Para Strauss ${ }^{1}$, ao identificar a possibilidade de desapossamento importante, o indivíduo está sujeito a "perder seu caminho por algum tempo" até reconstituir sua identidade ou desistir da ação. A perda da autonomia do corpo pode levar a mulher a abdicar daquilo que desencadeou o processo e gerar a desistência da amamentação.

Geertz $^{18}$ ressalta que "os fenômenos sociais geram impactos imediatos, profundos e decisivos" nas relações dos sujeitos, no self, na reconstrução da identidade, na ressignificação, na tomada de decisão. A mulher, diante da amamentação e sua autonomia corporal, do desejo de querer ou não amamentar, da experiência do amor materno, pode entrar em conflito pela dramatização destes aspectos de seu mundo associados que são a outros papéis que ela assume em 
diferentes relacionamentos sociais. Contudo, na perspectiva straussiana, a identidade é permeável a mudanças, assim o desapossamento, o perigo e a perda de autonomia do corpo podem ser eventos transitórios, um rito de passagem para a elaboração de uma nova identidade.

Esse processo de constante transformação da identidade mobiliza os propósitos centrais do $e u$, e envolve autodomínio e engajamento na ação. O indivíduo tem expectativas e faz juízo acerca do que o espera, e mesmo que determinada situação não lhe seja familiar, é o envolvimento que irá determinar a realização da ação. À medida que uma ação é altamente valorizada socialmente, implicar-se nela poderá ser igualmente importante. Assim, pode-se compreender como a maternidade e o engajamento subjetivo no processo do aleitamento materno não são apenas determinados pela natureza ou uma vocação nata da mulher, mas também e principalmente socialmente construídas. Ao passo que a mulher se compromete e se envolve com a maternidade e a amamentação é que vai sendo produzida socialmente sua capacidade de assumir esse papel; as mulheres passam a valorizar e a creditar mais importância ao papel de mãe em comparação aos demais que assume, ocorrendo aquilo que Strauss ${ }^{1}$ denominou de uma sobreposição de status. Ao agir de maneira diferente daquela esperada socialmente, a mulher pode ser precipitadamente estigmatizada como ser que "não nasceu para ser mãe".

Seguindo Strauss ${ }^{1}$, investir na realização de uma ação considerada socialmente importante como é o caso da amamentação, é investir em desempenho e habilidades para realizar tal ação. Quando ocorre profundo envolvimento no curso de uma determinada ação, pesa a identificação com ela. Portanto, há uma diversidade de situações possíveis: haverá a mulher que se identifica não somente com o papel da maternidade, mas também com a amamentação, haverá mulheres optando pelo não envolvimento com o status da amamentação ainda que assumindo e se engajando profundamente no papel de ser mãe, ou ainda mulheres que decidem pela adoção com ou sem a experiência da amamentação e finalmente aquelas que não optaram por nenhuma delas.

Assumirá voluntariamente o status da amamentação em tempo prolongado, a mulher que possuir identificação com o ato de amamentar, a tal ponto dos conflitos e dramas presentes em seu cotidiano poderem ser acolhidos e acomodados no processo de autoavaliação do self frente aos demais papéis sociais que assume em mundos sociais particulares.

\section{Interação social, maternidade e amamentação}

Para Strauss", a interação "significa encontros e as ações recíprocas que ocorrem entre as pessoas". É toda relação que abrange mais de um indivíduo em determinada ação considerando ainda seus aspectos motivacionais e as posições sociais envolvidas. Esta engrenagem do processo interacional é acionada pelo aspecto motivacional da ação e que na amamentação se ampara na maternidade. O status envolvido no papel de mãe, a simbologia e as relações de significado e importância construídas socialmente afetam fortemente a prática do aleitamento materno. Nesse sentido, o autor esclarece que o significado para a motivação ${ }^{1}$ "é o ato de identificar os objetos, quer físicos, quer humanos" e que permitirão a organização da ação com referência. Envolve fenômenos biológicos, psicológicos e sociais e pode ser o processo catalisador da ação.

Strauss ${ }^{1}$ ressalta ainda que há a possibilidade de explicar um determinado comportamento, mas justifica que para tal feito é necessário compreender a natureza das situações, dos papéis que os sujeitos assumem, e qual destes papéis se sobressai aos demais. Considerando que a classificação não está no objeto, mas o objeto pode ser classificado a partir de uma perspectiva, de um ponto de vista, são inesgotáveis os aspectos motivacionais (conscientes e inconscientes) envolvidos na nomeação.

Para Strauss", "o comportamento, mesmo com relação a objetos físicos, é situacional", ou seja, é a ação entre o objeto e a situação. Imputações motivacionais a um determinado comportamento remetem a uma ação, atribuir responsabilidade a algo ou qualificar motivos para justificar comportamentos é dar um destino à ação.

Seguindo a linha de pensamento de Strauss ${ }^{1}$, na interpretação da situação, a identidade é posta de maneira indefinida e envolve questões de colocação do self (autorretrato). Questionamentos como "quem sou eu nessa situação?", "o que fiz de relevante?", "o que farei será apropriado na situação ou para os motivos dos outros?” viabilizam a interpretação de uma determinada situação e orientam o comportamento. No caso do aleitamento materno perguntaríamos, "como será o papel de mãe com ou sem o aleitamento materno?", "como a mulher lida com as expectativas alheias (dos profissionais ou familiares, por exemplo) em relação à nutrição de seu bebê?", questões estas que forneceriam pistas sobre razões e como o status da amamentação é interpretado pela mulher. 
A interpretação pelo ato de prever, fantasiar e imaginar uma ação real também afeta consideravelmente a ação futura. Assim como racionalizar ou agir impulsivamente faz parte da interação social, os devaneios e as fantasias podem ocorrer. Em relação às mulheres diante da amamentação, quais seriam as interpretações (fantasias) consideradas para a não habilidade para amamentar? Uma possível resposta envolve a ideia do leite ser fraco ou insuficiente, talvez uma preocupação comum e frequentemente compartilhada por mulheres que não amamentaram ou a interromperam precocemente. Apesar de reconhecer sua natureza biológica para tal ação, ter motivação (manifesta pelo desejo), estar engajada na ação, e ter assumido o papel de mãe, finalmente não se reconhece hábil para o papel de amamentar porque hipoteticamente seu leite seria fraco. Durante a experiência do aleitamento materno, em um determinado momento certos sinais (como o choro do bebê, "a irritação") teriam sido ressignificados e antecipada uma interpretação baseada na premissa do "leite fraco" ou insuficiente. O leite fraco como uma fantasia que é compartilhada coletivamente em muitos espaços sociais - levando a uma inevitável interação - pode entrar no fluxo da interação particular de uma determinada mulher em situação de aleitamento materno.

Strauss ${ }^{1}$ considera a interação face a face um processo que se desenvolve em determinado curso. Os indivíduos envolvidos na interação face a face agem e respondem de forma complexa em relação ao e com o outro no desempenho de papéis, podendo englobar a atuação de terceiros (pessoas ou objetos) de modo a interferir na compreensão da ação. A mulher ao interpretar e assumir seu papel de mãe e lactante pode mencionar durante a interação com outras pessoas da família, amigos ou profissionais, sentimentos a respeito da maternidade (amor, desejo, angústia, frustração), do corpo (autonomia, percepção de capacidade corporal para alimentar), ou de sua insegurança sobre o quanto pode ser (in) suficiente o seu leite para o bebê. É relevante para suas interpretações o fato de pessoas significativas terem tido êxito na amamentação ou nas respostas (expressões linguísticas e paralinguísticas) dadas por terceiros em momentos interacionais associados à lactação.

O processo interacional está estruturado socialmente de acordo com os papéis que as pessoas desempenham no curso da interação. Diante da multiplicidade de papéis que um único indivíduo assume, poderá em determinado momento ou situação sobressair um em relação aos outros. As- sim ocorre com a maternidade, ora mãe-mulher, ora mulher-mãe ${ }^{19}$.

$\mathrm{Na}$ interação pode haver uma indução ou imposição de determinado status a um sujeito. A colocação ou atribuição de um status social está ligada aos julgamentos sociais a respeito. $\mathrm{O}$ sujeito poderá ou não assumir a posição que lhe é conferida, mesmo que temporariamente, e de forma ritualizada, como é o caso do resguardo após o nascimento do bebê.

Embora, muitas vezes, seja de competência do indivíduo assumir determinado status, os padrões culturais são sistemas propícios e pertinentes para sua colocação. Nascer e viver os múltiplos papéis sociais como mulher advém de nascer em um mundo já previamente ordenado em que o feminino é representado pela capacidade de amar, se doar e cuidar ${ }^{11}$.

Strauss ${ }^{1}$ considera que a consequência do "forçamento de status" deve levar em consideração se a colocação é temporária, permanente, incerta, reversível ou irreversível e, ainda, se o sujeito está preparado ou não para adotá-lo. Este autor refere ainda que quando existe um forçamento de status imputado ao sujeito, o mesmo poderá buscar táticas para impedir a atribuição (a outros e a si), podendo à medida que a interação progride, se perpetuar esta fuga de status. Strauss trabalha sociologicamente esta "fuga para aderir ao status" como uma espécie de negligencia de atribuições do status que implica em certo drama subjetivo e social.

Supondo que a mulher possa aceitar espontaneamente o status da maternidade, porém não aceite a imputação da perda de autonomia do seu corpo e da amamentação, neste caso ela assumiria o status, mas à medida que os fenômenos da amamentação se aproximam ou se realizam, pode criar mecanismos de fuga para não assumir o status de lactante ou abandoná-lo em um determinado período. Pode ainda, para reestabelecer sua identidade, submeter-se à aceitação temporária do status a fim de não quebrar interações sociais previstas.

O forçamento de status é uma condição concebida pelas estruturas sociais que convergem o indivíduo para experiências de insatisfação, seja pela não aceitação da colocação do status, seja quando o indivíduo não acredita merecê-lo ${ }^{1}$.

Nessa perspectiva, surge a reflexão sobre o sentimento de culpa concebido e pulsionado pela consciência moral e, portanto, sob influência social. O sentimento de culpa da mãe se refere à internalização de expectativas de condutas e comportamentos sociais previstos. O pensamento 
consciente sobre a inadequação de não amamentar, também é permeado pelo sentimento do dever e do desejo, a exemplo, "não desejo amamentar, mas devo fazê-lo”, pois implica em demonstração do amor materno, de comprometimento com o cuidado do bebê, do cumprimento com o "dever sagrado"8. O sentimento de culpa vem de fora para dentro, é o julgamento de outros sobre si, é julgar a sua ação mediante a reação dos outros, portanto representando um forçamento de status $^{1,2,7,8,9,16,20,21}$.

\section{Transformações na identidade}

As transformações da identidade se relacionam com mudanças de fases da vida e o desenvolvimento como um movimento progressivo não delimitado por um começo, meio e fim, mas como um processo de transformações relacionadas entre si na forma, no tipo ou no status psicológico do indivíduo. Toda mudança ocorre diante da aceitação de um desafio, imposto por si ou por outros, havendo alterações de (auto) concepções para adquirir um novo status, seja este social ou psicológico.

A experiência transformadora está estruturada na avaliação dos valores pessoais e sociais, em geral vinculadas a situações de conflitos. Tais experiências transformadoras condicionam a autoclassificação e a revisão do self. A experiência transformadora é uma etapa da passagem de status e está suscetível à revisão de conceitos, atitudes e comportamentos.

O movimento de passagem é institucionalizado e regulado para a ação. Sob a forma de advertências e sentimentos relatados pelo antecessor, experiências são transmitidas socialmente para o indivíduo como prognóstico de uma ação como, por exemplo, "todos temos que passar por isso algum dia", ou ainda "em sua idade, isso aconteceu comigo", "com meu filho foi assim". Na passagem de status (de mulher para mãe para lactante), a mulher, ainda na gestação começa a receber de outros indivíduos instruções, precauções, advertências relativas à amamentação, em um processo de preparação que se intensifica na medida em que se aproxima a chegada do bebê e se estende após o seu nascimento. $\mathrm{Na}$ realização da ação (amamentação), pode ocorrer a aceitação do status de modo organizado e na medida em que a mulher o percebe, compreende e valida ocorre uma autoavaliação do quanto será conveniente para si e para outros assumí-lo.

Já as explicações conflituosas comprometem a progressão e passagem de status, porque po- dem gerar confusão definicional. Nesse sentido, ao passo que a mulher está suscetível a receber diversas informações para prepará-la para a maternidade e amamentação, no caso dos relatos contraditórios e desencorajadores, gera-se a dúvida em relação à amamentação. Pode-se dizer que as explicações conflituosas e complicadoras funcionam como repelente para a admissão de um novo status e para realizar a ação.

Ainda, segundo Strauss ${ }^{1}$, outra ameaça de status incide quando a sua ocupação está acompanhada de conflitos agudos e que levariam ao abandono de qualquer sequencia regular das etapas. Sentimentos de desespero, desconfiança, insegurança e abandono se misturam e se sobressaem sobre o compromisso para realização da ação. O próprio medo favorece o abandono da amamentação, ou a insegurança sentida em relação ao seu leite nutrir satisfatoriamente o bebê.

Alguns status podem ser pré-definidos e por si só revelam as etapas e sua ação. Contudo, no caso do aleitamento as divergências na interpretação das fases da lactação ocorrem a partir de pontos de vista diferenciados, por exemplo, a visão materna de um lado e a opinião profissional de outro. Durante o processo da amamentação as mulheres que amamentam não percebem etapas distintas significativas na amamentação, enquanto nutricionistas, pediatras e enfermeiros dividem a amamentação em fases que se diferenciam segundo o valor nutricional do leite materno e a capacidade fisiológica do bebê. Exemplar neste sentido é a visão materna acerca dos primeiros dias após o nascimento, quando frequentemente a quantidade de colostro é interpretada como insuficiente para satisfazer a fome do bebê, sendo o choro da criança sentido com grande angústia pela mulher-mãe.

De outro lado, o preparo para a mudança de status via explicações e relatos de experiência pode favorecer a passagem e a realização da ação. Neste sentido, experiências de grupo, quando a mulher recebe orientações acerca da amamentação sobre o preparo físico, percepção da satisfação do bebê e possíveis dificuldades, promovem o aumento da consciência ou da bagagem de informações para a ação. Este preparo interfere na consciência sobre o processo somando a capacidade de a mulher decidir assumir o status da lactação.

Esta afiliação do sujeito a grupos sociais implica em ligações e identificações simbólicas e a vivência em grupo está pautada na comunicação, nos significados dos sentidos compartilhados. Experiências compartilhadas revelam uma ação 
comunitária para além da troca de informações. Partilhar posturas, comportamento e atitudes, não se reduz à mera comunicação formalizada, mas a dar sentido e significado sobre si, os outros e os eventos.

Para Strauss', "um status, tem a probabilidade de transformar-se tanto num modo de ser quanto num modo de agir", portanto é temporal (transitório, passageiro), seguido por certa cronologia social e pontuado por fases. Também já foi ressaltado como mudanças significativas da identidade se relacionam a fases decisivas na vida do sujeito. $\mathrm{Na}$ amamentação, o problema da autonomia do corpo feminino frente às demandas maternas sugere uma transformação de status. Em que pese ser um rito de passagem, transitório da vida da mulher, a autopercepção e os aspectos atitudinais ficam subjetivamente confrontados às recomendações de organizações de saúde e precisam ser compreendidos.

\section{Considerações finais}

O ciclo de vida humana é delineado socialmente havendo uma normatização e normalização das etapas e posições sociais. A amamentação é um fenômeno social multifacetado que envolve a complexidade do mundo social, os papéis assumidos pelas mulheres com seus atributos e expectativas. Ao mesmo tempo em que o desempenho da maternidade e o engajamento no status da amamentação são orientados por valores e referências do mundo social, $o$ ato de amamentar também envolve sutilezas subjetivas complexas.

Os papéis que cada membro da sociedade interpreta (máscaras) requer colocação de status (a exemplo a amamentação na maternidade), e autoavaliação do self (espelho), o que sempre ocorre em processos interacionais contínuos e fluídos.

Ser mãe e amamentar não são papéis sociais fixos que as mulheres se apropriam naturalmente e reproduzem harmoniosamente. São antes desafios e demandas construídas socialmente que envolvem ressignificação, conflitos e redefinição da sua identidade social.

Compreende-se que papéis definidos socialmente, ao localizarem a mulher apta pela sua natureza biológica no espaço do cuidar, o qual é subjugado politicamente, acabam reproduzindo relações assimétricas de poder entre homens e mulheres. Consequentemente, a cada vez que a mulher (re)interpreta seus desejos, muda suas posturas e ações, reatualiazam-se tensões próprias do modelo patriarcal.

Para Strauss ${ }^{1}$, as identidades representam não somente trajetórias biográficas pessoais, mas, sobretudo, histórias sociais. As identidades e os comportamentos a elas atrelados, mantêm-se ligados à organização social e à identidade do gru$\mathrm{po}^{22}$. Há, portanto, referências de quadros sociais e culturais que servem de subsídio para as mulheres construírem suas identidades que devem ser consideradas nas reflexões sobre a amamentação.

A maternidade e a amamentação são eventos biológicos que adquirem o valor e o significado que têm a partir de suas inscrições simbólicas e das construções sociais que a sociedade lhes confere. A atribuição à mulher de vocação à maternidade e ao aleitamento é que produz uma expectativa social de habilidade nata e desenvoltura para os mesmos ocultando outras dimensões do fenômeno da experiência de amamentar.

A amamentação como fato social não se restringe apenas a um meio de alimentar, mas expressa um modo de ser e estar socialmente. $\mathrm{O}$ ato de amamentar se relaciona a processos dinâmicos e complexos da identificação (nomear-se e autoclassificar-se lactante) com uma multiplicidade de conflitos, perspectivas que se abrem e são continuamente avaliadas. A desnaturalização do evento requer ainda refletir sobre a possibilidade da vivência da maternidade simultânea ao sentimento de não identificação com a lactação ou decisão de não amamentar. 


\section{Colaboradores}

RCF Giordani participou na concepção teórica e delineamento da estrutura do texto, redação e revisão crítica, e aprovação da versão a ser publicada. D Piccoli redigiu o artigo, realizou análise de fontes e interpretação. I Bezerra realizou revisão crítica. CCB Almeida realizou a revisão final da versão a ser publicada.

\section{Referências}

1. Strauss AL. Espelhos e Máscaras: A busca de identidade. São Paulo: DUSP; 1999.

2. Rodrigues J. Tabu do Corpo. Rio de Janeiro: Fiocruz; 2006.

3. Scott J. Gênero: uma categoria útil de análise histórica. Educação e realidade 1990; 16(2):5-22.

4. Martins A. Possibilidades de diálogo: Classe e gênero. História Social 1998; 4(5):135-156.

5. Foucault MP. Microfísica do poder. $12^{\mathrm{a}}$ ed. Rio de Janeiro: Graal; 1996.

6. Guzmam ES. Agroecología y agricultura ecológica: hacia una "re" construccion de la Soberanía alimentaria. Cordoba: Instituto de Sociologia y Estudios Campesinos; 2006.

7. Witzel D. Discurso, História e Corpo feminino em artigos de anúncios publicitários. Alfa 2014; 58(3):525539.

8. Badinter E. Um amor conquistado: o mito do amor materno. Rio de Janeiro: Nova Fronteira; 1985.

9. Lima A. Maternidade higiênica: natureza e ciencia nos Manuais de puericultura publicados no Brasil. História: Questões \& Debates 2007; 47:95-122.

10. Perrot M. Os silêncios do corpo da mulher. In: Matos M, Soihet R. O corpo feminino em Debate. São Paulo: Unesp; 2003. p. 13-27.

11. Beauvoir S. O segundo sexo. Rio de Janeiro: Nova Fronteira; 1980.

12. Hird M. The Corporeal Generosity of Maternity. Body \& Society 2007; 13(1):1-20.

13. Merleau-Ponty M. Fenomenologia da percepção. $5^{\mathrm{a}}$ ed. São Paulo: WMF Martins Fontes; 2006.

14. Giordani RCF. O corpo sentido e os sentidos do corpo anoréxico. Rev. Nutrição 2009; 22(6):809-821.

15. Goffman E. Representação do Eu na Vida Cotidiana. Petrópolis: Vozes; 1985.

16. Rodrigues I, Queiroz M. Compreensão da vivencia materna na amamentação. Revista RENE 2005; 6(2):9-17.

17. Ferreira ABH. Mini Aurélio: O dicionário da Língua Portuguesa. 8a ed. Curitiba: Editora Positivo; 2010.

18. Geertz C. A Interpretação das Culturas. Rio de Janeiro: Guanabara Koogan; 1998.

19. Abuchaim E. Vivenciando a amamentação e a sexualidade na maternidade: "dividindo-se entre ser mãe e ser mulher" [tese]. São Paulo: Universidade de São Paulo; 2005.

20. Lobo S. As condições do surgimento da "Mãe Suficientemente Boa". Revista Brasileira de Psicanálise 2008; 42(4):67-74.

21. Santos MA, Garcia RWD, Santos ML. Sujeição aos padrões corporais culturalmente construídos em mulheres de baixa renda. Revista Demetra 2015; 10(4):761774 .

22. Zanatta MS. Nas teias da identidade: contribuições para a discussão do conceito de identidade na teoria sociológica. Perspectiva 2011; 35(132):41-54.

Artigo apresentado em 30/05/2016

Aprovado em 05/09/2016

Versão final apresentada em 07/09/2016 
